\title{
Frei Elias Zulian: educação e missão na região de Ponta Grossa, PR (1952-1976)
}

\author{
Brother Elias Zulian: education and mission in the region of Ponta \\ Grossa, PR (1952-1976)
}

\begin{abstract}
Fray Elias Zulian: educación y misión en la región de Ponta Grossa, PR (1952-1976)
\end{abstract}

\section{Edson Claiton Guedes"}

Secretaria de Estado da Educação de Santa Catarina, Professor https://orcid.org/0000-0003-1641-2264

http://lattes.cnpq.br/2529969768157903

\section{Adriana Salvaterra Pasquini ${ }^{2}$}

Universidade Estadual do Paraná, Campus Apucarana, Professora do Departamento de Educação

https://orcid.org/0000-0001-8437-2773

http://lattes.cnpq.br/9391968775107114

Resumo: 0 presente texto analisa o papel desempenhado pelo Frei capuchinho Elias Zulian (1920-1976) no contexto educacional da região paranaense dos Campos Gerais, entre os anos de 1952 a 1976. Entendemos que anseios pessoais e institucionais influenciaram a atuação do religioso. Questionamos: qual o âmbito de atuação de Frei Elias no contexto educacional da região? Nascido em 9 de agosto de 1920 na cidade de Postioma, diocese de Treviso, ingressou ao seminário em 1932, sendo ordenado sacerdote em Veneza no ano de 1945. Em 1949 foi enviado como missionário ao Estado do Paraná, exercendo seu apostolado em Barra Fria (1949), Bandeirantes (1950-1951) e na Cidade de Ponta Grossa (1952-1976), assumindo a Capelania dos ferroviários da Rede Viação Paraná-Santa Catarina (RVPSC). Sua atuação extrapolou os limites do altar e culminou na estruturação de um importante aparato educacional. Para o desenvolvimento da investigação, realizou-se uma pesquisa documental em fontes primárias, como o Boletim Interno da Província Paraná e Santa Catarina e o Archivio Provinciali Cappuccini da Província São Lourenço de Brindes, bem como realizaram-se estudos bibliográficos relativos à Igreja, Estado e Educação enquanto espaço de disputa (Juan Esquivel e Riolando Azzi). Como método de análise, a pesquisa pautou-se na consideração de que a atuação dos indivíduos é determinada pela materialidade das condições históricas, ou seja, o Materialismo Histórico Dialético. A partir da análise das

Mestre em História, Cultura e Identidades pela Universidade Estadual de Ponta Grossa; Licenciado em Filosofia e História e Bacharel em Teologia pela Pontificia Universidade Católica do Paraná.

2 Doutora em Educação pela Universidade Estadual de Maringá; Mestre em Educação pela Universidade Estadual de Maringá. 
fontes constatamos que Frei Elias expressou os anseios da lgreja Católica e da sociedade. Suas ações serviram para a propagação da escola pública na região dos Campos Gerais do Estado paranaense. Palavras-chave: Historiografia da Educação. Educação. Frei Elias Zulian. Ordem dos Frades Menores Capuchinhos.

Abstract: This text analyzes the role played by the capuchin Friar Elias Zulian (1920-1976) in the educational context of the Paraná region of the Campos Gerais, between 1952 and 1976. We understand that personal and institutional desires influenced the performance of religious. We question: what is the scope of the work of Friar Elias in the education context of the region? He was born on August 9, 1920 in the city of Postioma, diocese of Treviso. He joined the seminar in 1932, being ordained a priest in Venice in the year 1945. In 1949 he was sent as a missionary to the State of Paraná, exercising his apostolate in Barra Fria (1949), Bandeirantes (1950-1951) and the City of Ponta Grossa (1952-1976), assuming the Chaplaincy of the Viação Paraná network-Santa Catarina (VPNSC). His performance extrapolated the boundaries of the altar and culminated in the structuring of an important eductional apparatus. For the development of the research, documentary research was carried out in primary sources such as the Internal Bulletin of the Paraná and Santa Catarina Provinces and the Archivio Provinciali Cappuccini of the Province São Lourenço de Brindes, as well as bibliographical studies related to church, state and Education as a space of dispute (Juan Esquivel and Riolando Azzi). As a method of analysis, the research was based on the consideration that the actions of individuals is determinated by the materiality of historical conditions, that is Dialectical Historical Materialism. From the analysis of the sources we found Friar Elias expressed the desires of the Catholic Church and of a society. Its actions served for the propagation of the public school in the Campos Gerais region of the State of Paraná. Keywords: Historiography of Education. Education. Friar Elias Zulian. Order of Minor Friars Capuchin.

Resumen: El presente texto analiza la función ejercida por el Fray capuchino Elias Zulian (1920-1976) en el contexto educacional de la región de Paraná nombrada de Campos Gerais, durante los años de 1952 a 1976. Entendemos que los anhelos personales e institucionales influenciaron la actuación del religioso. Cuestionamos: ¿̇Cuál es el ámbito de actuación de Fray Elias en el contexto educacional de la región? Nacido el 09 de agosto de 1920 en la ciudad italiana de Postioma, diócesis de Treviso, ingresó al seminario en 1932, tornándose sacerdote en Veneza en 1945. En 1949 fue enviado como misionero al Estado de Paraná, ejerciendo su apostolado en Barra Fria (1949), Bandeirantes (1950-1951) y en la ciudad de Ponta Grossa (1952-1976), en la que asumió la Capelania dos Ferroviários da Rede Viação ParanáSanta Catarina (RVPSC). Su actuación extrapoló los límites del altar y culminó en la estructuración de un importante aparato educacional. Para el desarrollo de la investigación se realizó una búsqueda documental en fuentes primarias como el Boletim Interno de la Provincia Paraná y Santa Catarina y el Archivio Provinciali Capuccini de la Provincia São Lorenço de Brindes, así como estudios bibliográficos relativos a la Iglesia, Estado y Educación como espacio de disputa (Juan Esquivel y Riolando Azzi). Como método de análisis, la investigación se basó en la consideración de que la actuación de los individuos es determinada por la materialidad de las condiciones históricas, es decir, el Materialismo Histórico 
Dialectico. A partir del análisis de fuentes constatamos que Fray Elias expresó los anhelos de la Iglesia Católica y de la sociedad. Sus acciones se valieron para la propagación de la escuela pública en la región de los Campos Gerais del Estado de Paraná.

Palabras clave: Historiografia de la Educación. Educación. Fray Elias Zurian. Orden de Frailes Menores Capuchinos.

Recebido em 13 de novembro de 2018

Aceito em 18 de abril de 2019

Publicado em 14 de maio de 2019

\section{INTRODUÇÃO}

A atuação e a influência da lgreja Católica no processo educacional, institucionalizado ou não, tem se constituído um importante campo de investigação para a historiografia da educação brasileira. A análise do legado de um religioso requer a consideração de fatores que, aparentemente, estão desvinculados do processo, porém se constituem em condicionantes para a elucidação dos objetivos aqui propostos.

Este artigo insere-se nesse contexto. Tem como tema a atuação do Frei capuchinho Elias Zulian à frente da Capelania dos ferroviários da Rede Viação Paraná-Santa Catarina (RVPSC). Propõe-se a refletir sobre as ações realizadas pelo Frei Elias no campo educacional que culminaram na estruturação de importantes instituições educativas, como - Jardim de Infância, a Escola Elementar, a Escola Primária, a Escola de Economia Doméstica, além do Cine Teatro Pax, todas localizadas na Cidade de Ponta Grossa, Estado do Paraná.

0 texto está estruturado em torno de três questões: em primeiro lugar procuramos contextualizar brevemente a estrutura da Ordem dos Frades Menores Capuchinhos (OFMcap); em segundo lugar, buscamos compreender a atuação do Frei Elias vinculada à OFMcap, considerando, ainda, o processo histórico de consolidação da Igreja Católica no Estado do Paraná, posteriormente analisado. Em terceiro lugar, analisamos as implicações da atuação do Frei Elias Zulian na estruturação do contexto educacional na Cidade de Ponta Grossa no período de 1952 a 1976.

A análise do contexto educacional, e, em específico, da atuação individual de determinado indivíduo, requer, a utilização de um método de análise que considere as múltiplas relações sociais, políticas e econômicas que engendram o referido contexto. Dessa feita, adotamos como método de análise o Materialismo Histórico Dialético. 
Nesse sentido, para consolidarmos a pesquisa bibliográfica realizamos os estudos relativos à lgreja, Estado e Educação enquanto espaços de disputa fundamentados em Juan Esquivel (2013) e Riolando Azzi (2008), bem como realizamos a análise documental das fontes primárias do Boletim Interno da Província Paraná e Santa Catarina e do Archivio Provinciali Cappuccini da Província São Lourenço de Brindes.

\section{MOUIMENTO FRANCISCANO E A REFORMA CAPUCHINHA: UM BREUE APANHADO HISTÓRICO}

0 movimento franciscano ou, como é denominado no meio eclesiástico católico, a "família franciscana" é constituído por um grupo de congregações masculinas e femininas que se inspiram em diferentes aspectos da vida de Francisco de Assis (1181/1182-1126). A família franciscana é dividia em três ordens, sendo a Primeira Ordem a OFM (Ordem dos Frades Menores), que se subdivide em outros três grupos: Conventuais, Capuchinhos e Observantes. A Segunda Ordem é formada pela vertente feminina, fundada por Clara de Assis (1194-1253), e constituída por conventos autônomos e organizados em federações pelo mundo. A Terceira Ordem, também conhecida como Ordem Franciscana Secular, é formada por dois grupos: a Ordem Terceira Regular, homens e mulheres com votos religiosos, e Ordem Terceira Secular, casais e solteiros sem votos religiosos (ROTZETTER, 2003, p. 40).

0 movimento franciscano agitou a Itália no século Xll e tornou-se um instrumento de revigoramento para a lgreja Católica, inserindo-se no movimento "Mendicante" que propunha a pobreza real como caminho de perfeição evangélica.

É importante destacar que ao considerarmos a dimensão religiosa do movimento franciscano, não o desvinculamos do plano da práxis. Pelo contrário, a compreensão da totalidade do franciscanismo só é possível à medida que consideramos os meandros da realidade social e econômica da sociedade medieval. Em virtude dos constantes conflitos havidos entre os seguidores de São Francisco, no que compreende a observância da Regra Franciscana, e de maneira ainda mais pontual com relação à pobreza, é que surgiu a Reforma dos Capuchinhos.

A Ordem dos Frades Menores Capuchinhos teve sua origem na Itália no século XVI, precisamente em 3 de junho de 1528, por meio da Bula Papal Religionis Zelus, expedida pelo Papa Clemente VII (1478-1534). Nos Estatutos de Albacina, um conjunto de orientações produzido em 1529, são descritas algumas opções pelas quais ocorreu a Reforma: "os pontos fundamentais sobre os quais insistem particularmente são a pobreza, a austeridade, a oração, a solidão e o silêncio." (D’ALATRI, 1998, p. 18). Os reformadores acusavam o grupo no 
poder de impedir a observância da Regra deixada por São Francisco e por isso requisitavam uma releitura sem interpretação (sine glosa) da regra. Frei Mateus de Bascio (1495-1552) e os irmãos consanguíneos Freis Ludovico e Rafael de Fossombrone são considerados os pioneiros da chamada Reforma Capuchinha. ${ }^{3}$

Conforme as contribuições do Frei capuchinho Lázaro Iriarte na obra clássica do franciscanismo intitulada História Franciscana, traduzida e publicada na Língua Portuguesa em 1985, a Bula Papal Religionis Zelus, direcionada a Ludovico e Rafael de Fossombrone, apresentava os seguintes pontos: faculdade para levar vida eremítica guardando a Regra de São Francisco, para usar barba e hábito com capuz piramidal e para pregar ao povo (IRIARTE, 1985, p. 243).

Ainda de acordo com o autor supracitado, uma vez expedida a Bula, inúmeros frades Observantes e alguns noviços se uniram aos Capuchinhos, o que acarretou a ampliação dos eremitérios e a necessidade de organizar, de modo planejado, a recémcriada Ordem Religiosa. Inicialmente, Frei Mateus de Bassio foi considerado o pai da Reforma Capuchinha. Entretanto o líder de direito, em razão da Bula Papal, foi o Frei Ludovico, que, em abril de 1529, convocou o primeiro Capítulo da Ordem formado por $१ 2$ religiosos, onde foram escritas as primeiras Constituições (IRIARTE, 1985, p. 243).

Ao considerarmos o contexto eclesial, podemos inferir que a busca por um franciscanismo autêntico levou os frades reformadores a uma configuração da regra e do testamento de Francisco de Assis para "satisfazer às evoluções e às novidades religiosas que apareceram nos primeiros decênios do século XVI." (MERLO, 2005, p. 262).

São Francisco de Assis emergiu como uma das principais figuras da Cristandade medieval e almejava, por meio da vivência evangélica, um novo estilo de vida religiosa inserido no mundo urbano e não dentro dos conventos, como era o estilo monástico. Não obstante, suas intenções e ideias foram, por vezes, utilizadas para justificar as cisões movidas por vaidades e anseios pessoais que ocorreram dentro da própria Ordem.

As disputas em torno da pessoa e da obra de Francisco de Assis configuraram expressões interpretativas, de maneira geral, divergentes, tanto a respeito da experiência primitiva do santo quanto da leitura sobre a maneira de observar seus conselhos. Dessas interpretações surgiram inúmeras formas de viver o carisma franciscano que, com o passar dos anos, institucionalizaram-se em congregações e ordens religiosas amparadas, em sua maioria, pela lgreja Católica Romana.

\footnotetext{
3 De acordo com o Frei Rovílio Costa, a Reforma Capuchinha foi um movimento dos Frades Observantes que almejavam recuperar o espirito original franciscano. Inicialmente eram chamados de Frades Menores de Vida Eremítica. Posteriormente, em razão do capuz, passaram a ser chamados Capuchinhos (COSTA; DE BONI, 1996).
} 


\section{OS MISSIONÁRIOS CAPUCHINHOS, A RESTAURAÇÃO CATÓLICA E O PROCESSO DE DIOCESANIZAÇÃO NO PARANÁ NO INÍCIO DO SÉCULO XX}

Com a proclamação da República e a separação dos poderes civil e eclesiástico, a lgreja precisou se reorganizar para implementar novas dioceses no País. É importante salientar que

\footnotetext{
no início da República (1889) havia no Brasil, apenas doze dioceses. 0 número reduzido de jurisdições diocesanas era incompativel com a dimensão territorial e populacional do país e se constituía no principal desafio para a expansão do catolicismo. Entre 1890 e 1930 foram inauguradas outras 56 dioceses, dezoito prelazias, três prefeituras apostólicas e numerosos seminários. (SERBIM, 2008, p. 95).
}

A presença mais intensa da lgreja deu-se mediante instituições de caráter religioso e/ou educativo, fortalecendo-se em um movimento encabeçado por Dom Leme, a partir de 1916, chamado de Restauração Católica. A Restauração Católica foi uma resposta da lgreja diante do projeto de laicização da sociedade brasileira pelo republicanismo, pois se sentia marginalizada da vida pública e social e serviu aos princípios centralizadores da Igreja de Roma sobre toda a sociedade brasileira (AZZI; GRIJP, 2008). Desde então, de acordo com Mesquida e Brighenti (2015), iniciou-se uma verdadeira guerra de posição por parte da hierarquia e intelectuais católicos em busca de uma hegemonia que teve na educação seu principal instrumento.

No Paraná, os Capuchinhos foram agentes importantes desse projeto. A presença e atuação da Ordem no Paraná deu-se, de acordo com Quaresma Filho (1968-1969), em dois períodos distintos: o primeiro, durante o Segundo Império e início da República (18401912), caracterizado pela atuação juntos aos indígenas nos aldeamentos. 0 segundo período, iniciado no ano de 1920, quando a Província Capuchinha de Veneza (Itália) assumiu uma missão no Sul e no Norte do Estado para atender os imigrantes italianos que chegavam.

No período imperial brasileiro, o trabalho dos frades junto aos aldeamentos respondia às demandas da época. Neste trabalho, destacaram-se os Freis Pacífico de Montefalco e Ponciano de Montaldo, que fixaram residência nas primeiras povoações no vale do Rio Itararé, território da então paróquia de São João Batista do Rio Verde, atual cidade paulista de Itaporanga no ano de 1840. Também os Freis Timóteo de Castelnuovo e Matias de Gênova, que, a partir do anos de 1854, estiveram na Colônia Militar de Jataí e Aldeia São Pedro 
de Alcântara, no vale do Rio Tibagi, hoje região pertencente a Jataizinho, como também os Freis Luiz de Cimitile e Gaudêncio de Gênova (QUARESMA FLHO, 1968-1969). Uma vez superada a necessidade do trabalho junto aos indígenas, os religiosos deixaram as terras paranaenses no ano de 1912.

A partir de 1920, sob a tutela de Dom João Francisco Braga, então bispo de Curitiba, os Capuchinhos regressaram ao Estado do Paraná para atuarem no processo de diocesanização. ${ }^{4} 0$ processo de diocesanização era uma forma de a lgreja responder à falta de estrutura que ficou mais evidente desde a separação com o governo, a partir da proclamação da República. A necessidade de criar novas dioceses, no entanto, esbarrou no reduzido número de religiosos para que tal projeto fosse viável.

Em 1892, com a Bula Ad Universas Orbis Ecclesias do Papa Leão XIII (1878-1903) foram constituídas as províncias eclesiásticas Norte e Sul, respectivamente, com sedes em Salvador e Rio de Janeiro, juntamente com a criação de outras duas dioceses em cada província, entre elas a Diocese de Curitiba, que envolvia o Estado de Santa Catarina, sendo sufragânea da sede metropolitana do Rio de Janeiro (AZZI, 2008; ESQUIVEL, 2013; VIEIRA, 2007).

Desde a criação dessas dioceses, houve um aumento do clero, que também se apresentava mais comprometido e preparado. Nessas circunstâncias, o modelo ultramontano da lgreja Católica passou a ser difundido no Estado do Paraná. 0 processo de diocesanização no Estado ocorreu em duas fases distintas, cuja temporalidade assim apresentamos: a primeira, inaugurada em 27 de abril de 1892 com a criação da Diocese de Curitiba, e a segunda fase a partir do ano de 1926, com a criação da Província Eclesiástica de Curitiba.

A criação da Diocese de Curitiba se deu em 27 de abril de 1892, por meio da Bula Ad Universas Orbis Ecclesias do Papa Leão XIII (1878-1903). Sua territorialidade se estendia ao Estado de Santa Catarina, sendo sufragânea da Sé Metropolitana do Rio de Janeiro, cujo primeiro bispo foi o Cônego José de Camargo Barros (1859-1906), eleito em 6 de janeiro de 1894, ficando à frente da Diocese até o ano de 1903, quando foi transferido para a Diocese de São Paulo.

Consideramos a criação da Diocese de Curitiba como um marco do início do projeto de romanização da lgreja Católica no Estado, cujo contexto é assim analisado por Dom Pedro Antônio Fedalto:

A situação do Brasil era precária, duas eram as forças que muito atuavam no fim do Império e início da República: a maçonaria e o positivismo de

\footnotetext{
4 Sobre o processo de diocesanização no Brasil indicamos a leitura da tese intitulada Modernidade Republicana e Diocesanização do Catolicismo no Brasil: a construção do bispado de Botucatu no sertão paulista (1890-1923), de autoria do professor Maurício de Aquino (AQUINO, 2012).
} 
Augusto Comte. Teixeira de Souza, o positivista brasileiro, afirmava que a República devia sua existência no Brasil aos positivistas da imprensa e do exército. Adotou uma atitude de tolerância para com o Catolicismo e impediu uma perseguição, como aconteceu na França, Espanha e Portugal. (FEDALTO, 2014, p. 144).

D. Pedro Antônio Fedalto ${ }^{5}$ considera a relação entre lgreja Católica e positivistas brasileiros pautada na tolerância, o que, em nossa análise, se deu de modo recíproco, uma vez que para a lgreja Católica também não interessava promover uma "guerra declarada" contra os representantes do Estado, conforme ocorrido na Europa.

\footnotetext{
A constituição brasileira era dominada pelo laicismo. Basta ver a bandeira e mesmo o Hino Nacional. 0 clero era mal formado com o concubinato em muitos casos, sem uma evangelização séria, uma religião devocional. Os sacerdotes eram poucos e muitos estrangeiros no Paraná. E nem todos eram dignos de sua vocação sacerdotal. Nesse clima é que foi criada a Diocese de Curitiba. (FEDALTO, 2014, p. 144).
}

0 bispado assumido por D. José de Camargo Barros era composto por 78 paróquias e nove curatos nos dois Estados (Paraná e Santa Catarina) para uma população de aproximadamente 700.000 habitantes, distribuída em uma região territorial de 295.458 quilômetros de extensão. Havia poucos padres, em um total de 68 no Paraná e Santa Catarina. Quarenta e três sacerdotes atuavam no Estado do Paraná dos quais 15 eram italianos, 15 poloneses, sete brasileiros, três portugueses, um ucraniano, um austríaco e um francês (COSTA, 1967).

A 2 de outubro de 1904 ocorreu na Diocese de Curitiba a posse do seu segundo bispo, Dom Duarte Leopoldo e Silva (1867-1938). Após dois anos à frente da Diocese Dom Duarte foi transferido para o Sólio Episcopal de São Paulo. Com sua transferência, o nome escolhido para substituí-lo foi o do D. João Francisco Braga, então bispo de Petrópolis, cuja posse ocorreu em 17 de fevereiro de 1908.

Como vértice dessa substituição, surgiu no contexto eclesial paranaense a figura de um bispo concatenado com as mudanças históricas da lgreja Católica no Brasil e também com o compromisso de inscrever os fiéis católicos do Estado, no processo de romanização católica e de luta diante dos desafios da República laica. 
Considerando o contexto histórico, é possível observar que a atuação de D. João Francisco Braga à frente do bispado da capital paranaense estava concatenada com a lgreja de Roma. Na Arquidiocese de Curitiba sua atuação na educação informal se expressou de modo profícuo por meio da estruturação das mais diversas pastorais e da imprensa local. No campo da educação formal, D. João não poupou esforços em viagens à Europa em busca de diferentes ordens religiosas para se instalarem na Arquidiocese paranaense e implementarem no Estado os colégios confessionais.

Quando em sua visita Ad Limina, ${ }^{6}$ ocorrida em maio de 1919, D. João Francisco Braga, bispo de Curitiba, solicitou junto ao Papa Bento XV (1854-1922) que enviasse missionários para auxiliarem na evangelização, tendo em vista que em 1910 havia 25.000 imigrantes italianos na Diocese de Curitiba (ARQUIDIOCESE DE CURITIBA, 1992). Nesse tempo, encontrava-se também em Roma o pregador apostólico Frei Lucas de Pádua, que sugeriu a D. João procurar pessoalmente o Provincial de Veneza Frei Serafim de Údine, então Ministro Provincial de Veneza para fazer tal solicitação (RIBEIRÃO PRETO, 1948). Segundo as Constituições capuchinhas, a fixação de uma Missão da OFMcap em determinada região exigia a realização de um convênio. Esse convênio, chamado de Convenzione fra, foi assinado em 16 de maio de 1919 em que foi firmado o contrato de prestação de serviços entre o Provincial de Veneza, Frei Serafim de Údine, e D. João Francisco Braga (QUARESMA FlLHO, 1968-1969).

0 convênio assinado explicitava a aceitação de D. João e de seus sucessores dos Freis Capuchinhos da Província de Veneza em sua diocese e concedia aos Freis o direito de construir conventos, formar uma província da Ordem e aceitar vocacionados. Em contrapartida os Capuchinhos aceitavam colaborar com o ministério apostólico nas paróquias da diocese, com exercício do ministério sacerdotal regido pelo Código de Direito Canônico estando também, sujeitos às leis da Ordem e sob supervisão dos próprios superiores regulares.

Em 17 de setembro de 1919, D. João e os missionários seguiram viagem no navio Principessa Mafalda, em direção ao Rio de Janeiro. Desembarcaram em 5 de outubro, ficando hospedados junto aos confrades da Província de Messina, no Rio de Janeiro, onde permaneceram até o dia 17 de dezembro, quando foram até São Paulo a fim de aguardarem a ordem de D. João para assumirem as Missões no Paraná. No relatório, Frei Ricardo de Vescovana, superior regular, assim descreve o período no Rio de Janeiro: “Esta parada foi para nós uma verdadeira providência em todos os aspectos, já até escrevemos um discursozinho em português que o professor está revendo." (CARTA DOS QUATRO..., 2015).

6 A visita Ad Limina Apostolorum, que significa visita aos túmulos dos apóstolos, que diz respeito também à reunião realizada com periodicidade de cinco anos entre o Bispo Diocesano e o Santo Padre. Prevista no Código de Direito Canônico nos seus cânones 399-400, é por meio dessa visita que o Papa é atualizado acerca das ações de cada diocese. 0 Bispo deve apresentar ao Sumo Pontífice um relatório sobre a estruturação e situação atual do prelado sob sua responsabilidade (ELWEL, 1988, p. 34). 
No Paraná, os Capuchinhos assumiram a pastoral paroquial e foram imediatamente designados para as paróquias de Cerro Azul, Tomazina e Colônia Mineira, atualmente Siqueira Campos. Frei Ricardo de Vescovana, foi nomeado vigário dessas paróquias, conforme documento de 28 de janeiro de 1920:

DOMINUS JOANNES FRANCISCUS BRAGA/ Dei et Apostolicae Sedis gratia/ Episcopus Curitibensis in Brasilia/ Omnibus haec lecturis salutem in Domino. Temos por bém nomear, enquanto não for determinado o contrário, encarregado, com todos os poderes paroquiais e faculdades A. B., dos territórios de Cerro-Azul, Tomazina e Colônia Mineira e em todos os lugares que constituem os sobreditos territórios, o Revmo. P. Frei Ricardo de Vescovana, que poderá fazer auxiliar no seu ministério paroquial, sempre que julgar necessário pelos seus companheiros Frei Angélico de Ênego, Frei Teófilo de Tiene e Frei Maximiliano de Ênego [...] (RIBEIRÃO PRET0, 1948, p. 25).

Posteriormente, Frei Ricardo solicitou junto ao Provincial a autorização para assumir a paróquia de Jaguariaíva, cuja distância de Cerro Azul é de $१ २ 0$ quilômetros ao Norte, o que facilitaria a comunicação dos Freis com o Bispo de Curitiba. Assim, Jaguariaíva tornou-se parte do território da Missão e a sede da Missão dos Capuchinhos no Paraná. 0 território de Missão abrangia uma região de $350 \mathrm{~km}$ de cumprimento e $100 \mathrm{~km}$ de largura, totalizando uma área de 3.500 kma. Estava dividida em duas regiões: a primeira ao Sul no Vale do Ribeira e a segunda ao Norte do Paraná (QUARESMA FLHO, 1968-1969).

Ainda de acordo com Quaresma Filho (1968-1969, p. 39), em 1 de junho de 1922, os Freis Capuchinhos passam a responder também pela Paróquia de Jacarezinho, bem como pelas capelas de Santo Antônio da Platina, Barra Grande (Guapirama), Saltinho, São Roque do Pinhal e Cambará. Posteriormente a direção do Grupo Escolar Paroquial Imaculada Conceição (Santo Antônio da Platina) também ficou sob a tutela dos frades. 0 trabalho dos missionários Capuchinhos expandiu-se rapidamente, e nos anos seguintes outras paróquias foram assumidas pela Ordem, o que acarretou na vinda de outros Freis da Província de Veneza para o Estado, somando, em 1947, um total de 47 frades italianos na missão paranaense.

\section{FREI ELIAS ZULIAN E A AFIRMAÇÃO DOS PRINCÍPIOS CATÓLICOS NA EDUCAÇÃO DOS CAMPOS GERAIS}

Com a criação da Diocese de Jacarezinho, em maio de 1926, ampliou-se também a atuação dos Freis Capuchinhos no Paraná, uma vez que a nova Diocese passava a abarcar praticamente toda a região Norte do Estado e alguns municípios dos Campos Gerais. 
Historicamente, as ordens e congregações religiosas assumiram, como regra geral, a dinâmica de renovação eclesial contrapondo-se ao aspecto hierárquico e conservador. Porém, de acordo com Azzi (2008), no Brasil os institutos atuaram mais no sentido de conservação de valores do que de renovação.

Mediante a implementação da Reforma Católica, a Santa Sé exigia por parte dos bispos a estruturação e o acompanhamento periódico junto ao clero, que, paradoxalmente, deparavam-se com uma escassez de leigos católicos preparados. Assim, designavam às ordens e congregações a demanda de frentes de ação que combatessem o principal adversário da lgreja Católica nas quatro décadas iniciais do século XX: o ensino laico e protestante. É nesse contexto que se insere a atuação do Frei Elias Zulian.

Eugênio Zulian (Frei Elias) nasceu em 9 de agosto do ano de 1920, em Postioma, na Província Italiana de Treviso. De acordo com as fontes disponíveis na Cúria da Província São Lourenço de Brindes dos freis capuchinhos, Frei Elias ingressou no Seminário localizado na Província de Rovigo em 1 de setembro de 1932. Vestiu o hábito capuchinho na Província de Bassano Del Grappa, emitiu os votos perpétuos em Veneza, onde foi ordenado sacerdote em 9 de setembro de 1945.

No dia 8 de julho de 1949, Frei Elias foi destinado por seu provincial como missionário ao Paraná. 0 embarque no porto de Gênova em 22 de outubro de 1949 é assim apresentado no número especial, Necrológio, do Boletim Interno da Província São Lourenço de Brindes:

\footnotetext{
Partiu de Gênova com frei Celestino Coletti aos 22.10.1949 no navio Anna Costa. Ao embarque estavam presentes um irmão, uma irmã, e sua mãe, dona Giovanna. Enquanto os irmãos choravam, a mãe, na sua dor, mas sem derramar uma lágrima, recordou-lhe o que havia dito antes do seu ingresso no Seminário: "Meu filho pense bem no que você está fazendo... Veja! A porta desta casa está aberta para sua partida, mas ficará fechada para o seu retorno. Assim the falei... Agora, após ter me pedido a bênção para a missão, a minha atitude não mudou. Vá e cumpra seu dever até o fim... Desta vez não quero chorar, pois sei que você está para assumir uma missão sacrossanta". "Eu, frei Elias, não aguentei e me prorrompi em prantos." Logo, seu companheiro, fr. Celestino de Veneza the animou o espirito. (BOLETIM INTERNO..., 2015, p. 88).
}

0 desembarque no porto da cidade paulista de Santos se deu em 9 de novembro de 1949. No mesmo ano Frei Elias iniciou suas atividades na cidade catarinense de Barra Fria; no ano seguinte foi enviado para o Estado do Paraná, na cidade de Bandeirantes, onde atuou até o ano de 1951, quando foi transferido para Ponta Grossa, no período de 1952 a 1976.

Nas paróquias onde passou, Frei Elias atuou como pároco, vigário e professor. Todavia, foi à frente da Capelania dos Ferroviários da Rede de Viação Paraná-Santa Catarina 
(RVPSC), ${ }^{7}$ com sede no Bairro de Oficinas, que ele atuou de modo ativo na estruturação de um "Aparato Educacional Católico".

De acordo com a historiadora Rosângela Wosiack Zulian (2015), o Bairro de Oficinas surgiu do fluxo ferroviário na região e da necessidade de manutenção dos maquinários. Dessa maneira, a aproximadamente três quilômetros do centro da cidade, estruturou-se um complexo para atender as demandas reais dos ferroviários:

\begin{abstract}
[...] com pátios de manobra e armazenamento de comboios, oficinas de locomotivas e vagões, estações de cargas e passageiros, depósitos, usinas de tratamento de dormentes entre outros. Integravam o sistema: a Vila dos Operários, a Cooperativa Mista 26 de Outubro, fundada em outubro de 1906, a Escola Profissional Ferroviária Cel. Tibúrcio Cavalcanti, de setembro de 1940, e ainda o Hospital 26 de Outubro. (ZULIAN, 2015, p. 6).
\end{abstract}

A 18 de maio de 1952, Frei Elias assumiu como capelão e assistente social da Capelania dos ferroviários com o objetivo de prestar atendimento espiritual aos moradores do Bairro de Oficinas e também aos moradores das regiões próximas às estações sob a jurisdição da Capela Ferroviária, que, segundo estatísticas da época, totalizavam 267 estações, distribuídas em uma extensão de três mil quilômetros (BOLETIM INTERNO..., 2015, p. 88).

A atuação de Frei Elias na Capelania dos ferroviários se deu de modo dinâmico, no que compreende sua função como clérigo e religioso, haja vista o legado expresso na edificação da lgreja Matriz São Cristóvão, da qual foi seu primeiro pároco. Entretanto, chamanos a atenção sua dedicação e empenho na estruturação das instituições educacionais que até o presente momento configuram enquanto espaço educativo na Cidade de Ponta Grossa.

A capacidade organizativa de Frei Elias culminou na estruturação da Ordem Terceira Franciscana dos Ferroviários Paranaenses (OTFFP), fundada no mês de maio de 1955, na lgreja São Cristóvão, no bairro de Oficinas, onde estava situada sua sede. A finalidade da OTFFP

[..] era programar e realizar obras de cunho social, cultural, educacional, de lazer, que mantivessem os trabalhadores do bairro em constante atividade. A ordem, nos primeiros momentos de sua criação, traçou um plano de desenvolvimento: jardim de infância para 100 crianças, curso primário para 300 crianças, moradia para 20 religiosas, escola doméstica para 60 moças e ainda um internato para 80 filhas de turmeiros, o qual tinha por 
objetivo formar meninas em trabalhos domésticos, para que posteriormente pudessem contribuir com a formação das crianças e disseminar o aprendizado no local. Para a execução das metas previstas, Frei Elias contava com a participação da comunidade, o apoio dos superiores e da diretoria da RVPSC que tinha interesse na realização das obras. Além disso, segundo a crônica "já ganhara o respeito e consideração da classe política da época". 0 terreno para as construções foi cedido em regime de comodato pela Rede Viação Paraná-Santa Catarina. (ZULIAN, 2015, p. 7).

A primeira edificação de cunho educativo empreendida por Frei Elias foi o Cine Teatro São Cristóvão. 0 auditório com capacidade para 400 pessoas, inaugurado em 1 de abril de 1956, trouxe para os moradores sessões de cinema e peças teatrais. Foi nesse espaço, também, que as crianças e os adolescentes recebiam de Frei Elias a catequese dominical.

Para compreendermos a atuação de Frei Elias na educação formal, consideramos necessário notar o contexto histórico no qual essa educação formal se insere. Bem sabemos que a escola forma o homem necessário à sua época. Assim, concordamos com Magalhães (2001) ao afirmar que a instrução pública cumpria o papel precípuo de "abrasileirar" os imigrantes que aqui aportavam.

Apesar do crescimento populacional, a oferta de escolas públicas no Estado era escassa. 0s Grupos Escolares ou Escolas Isoladas se constituíam em medidas estruturais econômicas, pois agrupavam duas ou mais escolas reunidas e funcionavam no mesmo local. De acordo com Nascimento (2006), na região dos Campos Gerais as poucas escolas públicas que funcionavam se encontravam em estado precário. É nesse ambiente que se insere a atuação de Frei Elias no contexto educacional formal.

0 informativo comemorativo alusivo aos sete anos de fundação da Capelania R.V.P.S.C sintetiza a linha de ação definida e criteriosamente levada a efeito por Frei Elias:

Fundada em 1950 pelo então diretor Cel. José Machado Lopes no constante esforço de solucionar seriamente o vasto e urgente problema social educacional na classe ferroviária, erigiu em $1^{\circ}$ de maio de 1955 , uma entidade autônoma e integrada de bons elementos ferroviários, sob a orientação do Pe. Capelão e assistente social da RVPSC que é orientador e fundador da entidade. (A CAPELANIA DA R.V.P.S.C, 1961, p. 1).

É importante salientar que a preocupação com a educação dos ferroviários estava vinculada às demandas impostas socialmente. Com o desenvolvimento industrial era necessário preparar os trabalhadores e os filhos dos trabalhadores para responderem às novas exigências sociais. No mesmo periódico Frei Elias apresenta um demonstrativo das obras edificadas no contexto educacional, as quais estruturamos no Quadro a seguir: 
Quadro 2 - Obras educacionais de Frei Elias

\begin{tabular}{|l|l|l|l|}
\hline \multicolumn{1}{|c|}{$\begin{array}{c}\text { Data de } \\
\text { inauguração }\end{array}$} & \multicolumn{1}{|c|}{ Instituição } & \multicolumn{1}{|c|}{ Caracterização } & $\begin{array}{l}\text { Sessões e Alunos } \\
\text { matriculados }\end{array}$ \\
\hline $\begin{array}{l}1 \text { de abril de } \\
1956\end{array}$ & $\begin{array}{l}\text { Auditório Cine Teatro São } \\
\text { Cristóvão. }\end{array}$ & $\begin{array}{l}\text { Auditório com capacidade para } 400 \\
\text { pessoas. }\end{array}$ & $\begin{array}{l}\text { Quatro sessões } \\
\text { semanais com } \\
\text { ótima frequência }\end{array}$ \\
\hline $\begin{array}{l}18 \text { de fevereiro } \\
\text { de } 1957\end{array}$ & $\begin{array}{l}\text { Inauguração da Escola Isolada } \\
\text { da Vila Ferroviária. }\end{array}$ & $\begin{array}{l}\text { Capacidade para atender 126 alunos. } \\
\text { No ano de 1957, atendeu provisoria- } \\
\text { mente o Curso Primário. }\end{array}$ & 60 alunos \\
\hline $\begin{array}{l}18 \text { de fevereiro } \\
\text { de 1958 }\end{array}$ & $\begin{array}{l}\text { Por meio do Decreto n. 16768 } \\
\text { de 23/05 passou à categoria } \\
\text { de Grupo Escolar Jesus Divino } \\
\text { Operário. }\end{array}$ & $\begin{array}{l}\text { Foram inauguradas mais quatro } \\
\text { confortáveis salas de aula, acres- } \\
\text { centadas às existentes, as quais } \\
\text { ampliaram as atividades do Instituto } \\
\text { e permitiram a sua oficialização. }\end{array}$ & 430 alunos \\
\hline $\begin{array}{l}13 \text { de março } \\
\text { de 1961 }\end{array}$ & $\begin{array}{l}\text { Escola Doméstica e moradia das } \\
\text { professoras religiosas das Irmãs } \\
\text { Franciscanas Missionárias do } \\
\text { Coração Imaculado de Maria. }\end{array}$ & $\begin{array}{l}\text { Parte do prédio passou a ser } \\
\text { utilizado para acolher as filhas dos } \\
\text { ferroviários que estudariam em } \\
\text { regime de internato. }\end{array}$ & 55 alunas \\
\hline $\begin{array}{l}\text { Setembro de } \\
1964\end{array}$ & Cine Teatro Pax. & & \\
\hline
\end{tabular}

Fonte: elaborado pelos autores com base em A Capelania da R.V.P.S.C (1961, p. 1).

No que compete ao Grupo Escolar Jesus Divino Operário, julgamos necessário explicitar as mudanças ocorridas em razão das reformas educacionais. De acordo com o Projeto Político-Pedagógico da Escola Estadual Divino Jesus Operário

No ano de 1976, por meio do decreto $n^{\circ} 1925$ de 09/06/1975 a escola passou a ser denominada Escola Divino Jesus Operário, que funcionava anexa ao Ginásio Pax. Em 1982, com cessação das atividades do Ginásio Pax, a Escola Estadual Divino Jesus Operário passou a ofertar o ensino de $1^{\circ}$ grau, conforme resolução $n^{\circ} 579 / 84$. Em 1998, passou a chamarse Escola Estadual Jesus Divino Operário - Ensino Fundamental, conforme Deliberação $n^{\circ}$ 003/98 do Conselho Estadual de Educação publicada em D.0.E. do dia 16 de julho de 1998 e da Resolução nº 3120/98 da Secretaria de Estado da Educação publicada em D.0.E. do dia 1 de setembro de 1998. Diante do processo de municipalização das séries iniciais de ensino, $1^{\circ}$ de outubro de 2001, ocorreu o desmembramento do ensino de $1^{\circ}$ a $4^{\circ}$ série do Ensino Fundamental, que passou a ser mantido pela Secretaria Municipal de Educação, mas continuará no mesmo prédio, em espaço compartihado até abril do ano letivo de 2006. A partir dia 07 de abril do ano de 2006, já com prédio próprio, começou a funcionara Escola Municipal Frei Elias Zulian, deixando então de ser compartilhado o nosso prédio com o município. (ESCOLA ESTADUAL JESUS DIVINO OPERÁRIO, 2010, p. 8).

Consideramos, a priori, que as trajetórias individuais ou coletivas, como no caso de uma ordem religiosa, devem ser analisadas nas diferentes configurações que compõem 
sua totalidade: social, econômica, política e cultural, considerando, ainda, o sincronismo e o diacronismo dessas relações. Isso significa situar as ações aparentemente advindas de anseios pessoais, como fruto do desenvolvimento histórico e não como fatos ocasionais e isolados.

Dessa feita, ao analisarmos as ações realizadas por Frei Elias e capitaneadas pelas autoridades políticas da região do Bairro de Oficinas, percebemos que a estruturação de um "Complexo Educacional" esteve atrelada a uma necessidade econômica e socialmente estabelecida pelas exigências históricas. Frei Elias esteve concatenado com as exigências reais do ambiente no qual estava inserido. Homem do seu tempo, apropriou-se de um contexto cultural pouco familiar e tão logo compreendeu que a educação se constituía em um importante instrumento de "acomodação" a uma nova ordem social.

\section{CONSIDERAÇÕES FINAIS}

É fecundo indagar a função ideológica e histórica efetiva que esse religioso exerceu no processo de busca da identidade de uma lgreja em construção, em concomitância com a também construção de uma identidade educacional no Estado paranaense.

Fundada em 1950, para atender as necessidades das famílias e dos ferroviários vinculados à Rede Viária Paraná-Santa Catarina (RVPSC), a Capelania RVPSC, tendo como capelão o Frei Elias Zulian, tornou-se um importante instrumento de estruturação de um aparato educacional no Bairro de Oficinas, em Ponta Grossa, PR. À frente da Capelania assumida em 1952 a preocupação e o apostolado de Frei Elias não se restringiram ao trabalho paroquial, pois ele atuou de modo ativo na edificação de instituições educacionais.

Considerando que a escola pública foi eleita como uma das principais instituições a contribuir para a implantação, solidificação e manutenção da ordem política, social e econômica, percebemos que o plano de ação de Frei Elias estava concatenado com os objetivos da lgreja. Dessa maneira, seus esforços na implementação da educação como frente de trabalho pastoral contribuíram para a expansão e estruturação da escola pública em terras paranaenses, de modo particular, na região dos Campos Gerais.

\section{REFERÊNCIAS}

A CAPELANIA DA R.V.P.S.C. Sete anos de atividade. Ponta Grossa: Gráfica ldeal, 1961.

A FERROVIA DO CONTESTADO. Histórico. Disponivel em: http://www.histedbr.fe.unicamp.br/revista/revis/ revis16/img1_16.pdf. Acesso em: 9 maio 2016. 
AQUINO, M. Modernidade republicana e diocesanização do catolicismo no Brasil: a construção do bispado de Botucatu no sertão paulista (1890-1923). 2012. 301 f. Tese (Doutorado) - Faculdade de Ciências e Letras de Assis, Universidade Estadual Paulista, 2012. Disponivel em: http://hdl.handle. net/11449/103158. Acesso em: 7 jul. 2015.

ARQUIDIOCESE DE CURITIBA. A Arquidiocese de Curitiba em sua história e Diocese de Curitiba: 100 anos. Curitiba: Arquidiocese de Curitiba, 1992.

ARQUIDIOCESE DE CURITIBA. Dom Pedro Antonio Marchetti Fedalto. Disponivel em: http://arquidiocesedecuritiba.org.br/bispos/Dom-pedro-marchetti-fedalto/. Acesso em: 12 jul. 2015.

AZZI, R. A lgreja Católica na formação da sociedade brasileira. São Paulo: Santuário, 2008.

AZZI, R.; GRIJP, K. V. der. História da Igreja no Brasil. Ensaio de interpretação a partir do povo. Tomo II/3-2. Terceira época 1930-1964. Petrópolis: Vozes, 2008.

BOLETIM INTERNO da província do Paraná e Santa Catarina. Necrológio: Província São Lourenço de Brindes, Curitiba, ano 47, 2015. Edição especial.

CARTA DOS QUATRO missionários, 08 de outubro de 1919. Archivio Provinciali Cappuccini: Cúria Provincial São Lourenço de Brindes, Curitiba, 2015.

COSTA, R.; DE BONI, L. A. Os Capuchinhos no Rio Grande do Sul. Porto Alegre: Edições Est, 1996.

COSTA, 0. R. G. As fontes primárias existentes no arquivo da Sé Metropolitana e Paróquia de Nossa Senhora da Luz de Curitiba. In: SIMPÓSIO NACIONAL DOS PROFESSORES UNIVERSITÁRIOS DE HISTÓRIA, 4., 1967, São Paulo. Anais [...] Porto Alegre: ANPUH, 1967. p. 625-667.

D’ALATRI, M. Os capuchinhos: história de uma família Franciscana. Tradução: Adelino Piloneto. Porto Alegre: Edições Est, 1998.

ELWEL, W. A. Enciclopédia histórico-teológica da lgreja Cristã. São Paulo: Vida Nova, 1988.

ESCOLA ESTADUAL JESUS DIVINO OPERÁRIO. Projeto político-pedagógico, 2010. Ponta Grossa, 2010. 29 p.

ESQUIVEL, J. C. Igreja, estado e poĺtica: estudo comparado no Brasil e na Argentina. Aparecida: Santuário, 2013.

FEDALTO, P. A. M. História da lgreja no Paraná: contribuição de Dom Pedro Antônio Marchetti Fedalto para a celebração do jubileu de ouro da Regional Sul 2 da CNBB. Curitiba: CNBB Regional Sul 2, 2014.

IRIARTE, L. História franciscana. Petrópolis: Vozes, 1985.

MAGALHÃES. M. B. de. Paraná, Política e Governo. Curitiba: SEED, 2001. (Coleção História do Paraná Textos introdutórios). 
MERLO, G. Em nome de São Francisco: História dos frades Menores e do Franciscanismo até inícios do século XVI. Tradução: Frei Ary Pintarelli. Petrópolis: Vozes, 2005.

MESQUIDA, P.; BRIGHENTI, M. F. Dom Leme, os intelectuais e o papel da educação na reconquista da hegemonia católica: a guerra de posição de 1915 a 1950. Disponivel em: http://www.histedbr.fe.unicamp. br. Acesso em: 14 dez. 2015.

NASCIMENTO, M. I. M. Grupos Escolares na Região dos Campos Gerais (PR). In: VIDAL, D. G. (org.). Grupos Escolares - Cultura Escolar Primária e Escolarização da Infância no Brasil (1893-1971). Campinas: Mercado e Letras Edições e Livraria, 2006. p. 323-340.

QUARESMA FLLHO, H. Presença e ação dos Capuchinhos no Paraná. Revista Atos, Ponta Grossa, ano 1, nov. 1968/mar. 1969.

RIBEIRÃO PRETO, I. A custódia provincial dos padres Capuchinhos: nos estados do Paraná e Santa Catarina de 1920 aos nossos dias. Santo Antônio da Platina: Convento de Santo Antônio, 1948.

ROTZETTER. A. Com Deus nos dias de hoje: curso básico de vida franciscana. Petrópolis: Vozes, 2003.

SERBIM, K. Padres, Celibato e conflito social: uma história da lgreja Católica no Brasil. Tradução: Laura Teixeira Motta. São Paulo: Companhia das Letras, 2008.

VIEIRA, D. R. 0 processo de reforma e reorganização da lgreja no Brasil (1844-1926). Aparecida: Santuário, 2007.

ZULIAN, R. W. Uma experiência de cristianização do mundo do trabalho: Frei Elias Zulian e os ferroviários (1950-1976). In: CONGRESSO INTERNACIONAL DE HISTÓRIA UEPG - UNICENTRO, 2., 2015, Ponta Grossa. Anais eletrônicos [...] Ponta Grossa: UEPG, 2015.

Endereços para correspondência: Rua Padre Raulino Reitz, 365, Apto. 305, bloco 3, Bairro Serraria, 88113-120, São José, Santa Catarina, Brasil; nosdek@gmail.com. 
